\title{
Raza, género y colonia en la novela de Vicente Riva Palacio: una estrategia de exclusión
}

\author{
Alejandra PALAFOX MENEGAZZI \\ alexgnd@ugr.es \\ Universidad de Granada
}

\begin{abstract}
RESUMEN
El artículo analiza la contribución de la novela histórica Monja y casada, virgen y mártir de Vicente Riva Palacio en la construcción de un imaginario nacionalista liberal atravesado por amplias desigualdades sociales, étnicas y de género. Para ello, se aborda la estrategia narrativa desarrollada en la obra, centrando la atención en la verosimilitud pretendida y en los perfiles sociales dibujados en la misma, relacionando estos elementos literarios con el marco histórico contemporáneo en el que fueron producidos. Su selección responde a la extraordinaria influencia que tuvo en la creación de la identidad nacional mexicana, la regulación de la feminidad en la construcción liberal y el mito que convirtió a la Inquisición en sinónimo de intolerancia, crueldad y opresión.
\end{abstract}

Palabras clave: género, nacionalismo, indígena, reforma, novela.

\section{Race, gender and colony on the novel by Vicente Riva Palacio: an exclusionary strategy}

\begin{abstract}
The article discusses the contribution of the historical novel Monja y casada, virgen y mártir of Vicente Riva Palacio in the building of a liberal nationalist imaginary crossed by social, ethnic and gender broad inequalities. To do this, the narrative strategy developed in the work is approached, focusing on the alleged credibility and social profiles drawn in it, relating these literary elements with contemporary historical context in which they were produced. This selection responds to the extraordinary influence that it had on the creation of Mexican national identity, the regulation of the femininity in the liberal construction and the myth that did the Inquisition became synonymous with intolerance, cruelty and oppression.
\end{abstract}

Keywords: gender, nationalism, indigenous, reform, novel.

SUMARIO: 1. Introducción. 2. Estrategia temporal e historicidad de la obra. 3. "El vulgo no es más que el vulgo". 4. Homogenización étnica y nación. 5. Mujer y nación en el proyecto liberal. 6. El ideal femenino en la novela. 7. Conclusiones. 


\section{Introducción}

Este estudio parte de la premisa de que antes del estallido de los procesos de independencia política iberoamericanos no es posible constatar la existencia de naciones coincidentes con las formaciones estatales que se dieron en el siglo XIX. En atención con la, ya clásica, definición de nación de Benedict Anderson como "comunidad política imaginada inherentemente limitada y soberana" (Anderson, 1993: 21), la presencia de múltiples soberanías, de carácter principalmente autonómico, desde los inicios de los movimientos independentistas en Iberoamérica, probó la ausencia de un proyecto nacionalista consolidado anterior al establecimiento de los nuevos estados. En el caso mexicano, a esta situación se sumó el desarrollo de un heterogéneo sistema de adscripciones, pertenencias y fidelidades que habían convivido durante la época colonial junto con una variable pero, a grandes rasgos, visible fidelidad a la Monarquía Española y a la Iglesia, lo que constituyó un importante obstáculo ante la implantación de un sistema de lealtades homogéneo y coincidente con las estructuras formales de la nueva realidad independiente.

La construcción liberal del concepto de nación estuvo aunada en el México independiente a los principios de secularización, representación política y constitucionalismo. A partir de estos ejes vertebradores, se forjó un modelo de organización política y social, en parte continuador del proceso de modernización estatal iniciado con los Borbones, que trató de imponerse a lo largo de todo el siglo XIX y que estuvo basado en la defensa de la tolerancia religiosa, la igualdad ante la ley, el individualismo y la ciudadanía, así como en la natural existencia de una comunidad culturalmente homogénea, cuya historia común justificaba la implantación del nuevo Estado.

La organización territorial defendida desde estas instancias liberales fue continuadora del modelo gaditano y relegó el poder municipal a una posición secundaria con respecto al Estado. La implantación de este modelo administrativo, sin embargo, tuvo que lidiar en la práctica con la presencia de otras formas de nación sujetas al poder político del municipio y a la soberanía de los pueblos, entendida como un derecho inalienable ligado a la propiedad comunal de la tierra. De esta manera, tuvo lugar una confluencia de múltiples comunidades políticas imaginadas, autoidentificadas culturalmente, atravesadas por un componente étnico, y adscritas a un territorio concreto no coincidente con el estatal. Al mismo tiempo, la realización de este proyecto de nación liberal tuvo que hacer frente a la presencia de diversas formas de entender y vivir el nuevo orden republicano: otras lealtades, usos y costumbres que, si bien no cuestionaban la organización territorial de la nación, tampoco se adecuaban a la normativa ciudadana.

Vicente Riva Palacio, quien formó parte de la primera generación de intelectuales polifacéticos nacidos tras la ruptura política con la metrópoli española, advirtió pronto las trabas que el país presentaba para la consolidación de un aparato simbólico nacional que permitiese llevar a cabo el deseado proyecto político liberal. Nacido 
en el seno de una importante familia de la capital mexicana ${ }^{1}$, cursó los estudios de abogacía y logró en 1854, con tan sólo 23 años, ocupar el cargo de regidor del Ayuntamiento de la ciudad de México. Tras la cruenta Guerra de Reforma, que enfrentó a conservadores y liberales entre diciembre de 1857 y enero de 1861, este novelista consolidó su adhesión a los principios anticlericales y a la política defendida por el presidente Benito Juárez, consistente en la limitación de los privilegios eclesiásticos y el reforzamiento del Estado frente a los intereses corporativos, dentro de un marco ideológico liberal.

En 1861 El Monitor Republicano ${ }^{2}$ anunció que el Gobierno había autorizado a Riva Palacio la sustracción y publicación de una serie de documentos inquisitoriales ocultos hasta el momento en el Arzobispado de México. El objetivo de esta tarea no era otro que el de dar a conocer a los mexicanos la histórica influencia e intervención que el Santo Tribunal había ejercido en la sociedad, la familia y el individuo, los principios que lo habían sostenido y los reproblables métodos utilizados durante los procesos incoados por este organismo, incluyendo el tormento (Riva, 1861: 3).

Tras el enfrentamiento armado y ante la necesidad de consolidar la victoria militar y el proyecto de estado-nación liberal, poner de manifiesto los abusos perpetrados por el poder eclesiástico durante la época colonial parecía una buena estrategia para incrementar los apoyos sociales al nuevo gobierno juarista, fomentar la identidad nacional del país y contribuir a erradicar la "pesada mole de la ignorancia popular" (Altamirano, 1949: 602) ${ }^{3}$. Con estos objetivos, Riva Palacio aceptó la propuesta de llevar a cabo una selección crítica del material documental incautado para la redacción de un libro que evidenciara este oscuro pasado eclesiástico.

El inicio de la Guerra de Intervención en 1862, meses después de que Juárez hubiese realizado su encargo, truncó temporalmente la realización del proyecto. La activa participación que Riva Palacio tuvo en este conflicto bélico y la posterior instauración del Imperio de Maximiliano de Habsburgo le obligaron a dejar de lado la esperada y pedagógica tarea. A pesar de ello, una vez derrotados el ejército francés y el partido conservador, decidió retomar la empresa interrumpida y emplear algunos de los procesos inquisitoriales consultados para dar forma a una serie de novelas históricas y de folletín. Monja y casada, virgen y mártir formó parte de este conjunto literario y en 1868 apareció publicada por entregas semanales en el periódico satírico La Orquesta ${ }^{4}$. Pese a publicarse por primera vez en un diario de crítica

${ }^{1}$ Fue hijo del abogado y político moderado Mariano Riva Palacio y nieto, por vía materna, del héroe libertador Vicente Guerrero.

2 Diario liberal "radical” fundado en 1844 por Vicente García Torres e impreso hasta 1896.

${ }^{3}$ Esta expresión pertenece al intelectual liberal, literato y amigo de Riva Palacio, Ignacio Manuel Altamirano y refleja la perspectiva compartida por nuestro autor en la novela analizada.

${ }^{4} \mathrm{Al}$ tener un costo reducido, los periódicos poseían un poder de difusión mayor que el de los libros. 
política, escrito y leído, principalmente por varones, la novela de Riva Palacio estuvo dirigida a un público femenino, como explicita el autor a lo largo de sus páginas, al referirse en diversas ocasiones a sus "lectoras".

\section{Estrategia temporal e historicidad de la obra}

Pese a tratarse de un texto novelado, Riva Palacio intercaló datos históricos y ficticios, dotando a su obra de la veracidad requerida para convertirla en un instrumento legitimador de las medidas liberales, difusor del imaginario nacional e impulsor de la identidad mexicano-mestiza que se estaba construyendo (Riva, 1868: 5, 37). La obra fue así interpretada como un documento histórico, fundamentado en datos fehacientes y no ya como una novela inspirada en un número limitado e intencionalmente seleccionado de procesos inquisitoriales y crónicas de la época (Sook Kim, 2007: 53-68).

El marco espacial y cronológico elegido por Riva Palacio para la narración de su novela, la ciudad de México entre 1612 y 1624, no fue casual, sino que respondió a la oportunidad de establecer un paralelismo subliminar entre el conflicto entre liberales y conservadores por el cese de los privilegios eclesiásticos y el enfrentamiento entre el virrey D. Diego Carrillo de Mendoza y Pimentel y el arzobispo D. Juan Pérez de la Cerna. Por otro lado, la supuesta revuelta y posterior ejecución de treinta y tres afro-descendientes, acusados de instigar una rebelión esclava en 1612, incrementó el control sobre esta población capitalina en los años siguientes por parte de las autoridades, por lo que estos años ofrecieron para el autor un buen ejemplo para poner de manifiesto y denunciar la excesiva severidad empleada tanto por la Inquisición como por las autoridades virreinales en la época.

Otro de los elementos centrales en la estrategia narrativa de Riva Palacio fue la reconstrucción de la relación entre la población capitalina y el Tribunal del Santo Oficio en términos jerárquicos y opresores. En atención a lo descrito, la Inquisición procedía contra un individuo "por cualquier denuncia": "el más leve indicio, la menor sospecha bastaba para prender un hombre" (Riva, 1868: 480). La vinculación que, de una u otra manera, se estableció entre, prácticamente, todos los personajes de la obra y el Tribunal de la Fe muestra una cuasi omnisciente presencia de esta institución en la capital novohispana y la cotidianidad de sus habitantes quienes, prácticamente, vivían esperando que en cualquier momento una falsa denuncia los encerrase de por vida o los condenara a la hoguera.

Esta distorsión histórica distó mucho del respaldo y aceptación que la Inquisición tuvo entre gran parte de la sociedad novohispana hasta los últimos años del dominio colonial (Suárez, 1994: 365). La institución inquisitorial se mantuvo durante siglos gracias, en gran parte, al apoyo recibido desde diversos ámbitos poblacionales. Solo a inicios del siglo XIX, en el marco de las luchas independentistas, a causa de la represión que la Inquisición ejerció en apoyo del sector realista, esta institución perdió el importante respaldo social con el que había contado hasta el momento (Feher, 2010: 99-135). Por otro lado, entre 1571 y 1700, tuvieron lugar 
menos de dos mil procesos inquisitoriales, un número muy inferior que el que se desarrolló sólo en otras ciudades españolas durante esos años, como Zaragoza, Valencia o Granada (Alberro, 1998: 168). Cabe advertir, además, que desde 1571, por Cédula Real, la población indígena, mayoritaria en el Virreinato, dejó de estar sujeta a la jurisdicción inquisitorial ${ }^{5}$.

En consideración de los datos ofrecidos por Solange Alberro, la Inquisición mexicana ejecutó una media de quince procesos anuales, de los que, sólo el $1 \%$ concluyeron con la relajación en persona ${ }^{6}$ y el 3,4\% en estatua ${ }^{7}$ del acusado (Alberro, 1998: 208). Estas limitadas proporciones distan notablemente de la imagen de constante terror y control inquisitorial dibujada por Riva Palacio en Monja y Casada.

La novela centra su atención en el proceso iniciado contra Blanca de Mejía por su huida del convento en el que se hallaba recluida y el sacrílego matrimonio contraído siendo aún religiosa. Tras su detención y tormento, Blanca confiesa ser hereje y haber pactado con el demonio por lo que es condenada a morir por garrote. Si bien el delito de matrimonio de religiosos era castigado por la Inquisición con penas que iban desde la suspensión de las órdenes, la privación de sus bienes y la reclusión del acusado (García-Molina, 1999: 49), el delito de herejía, por el que la protagonista de la novela es condenada, admitía penas corporales, incluyendo la hoguera.

El porcentaje de las condenas a muerte por herejía, sin embargo, no fue representativo: entre 1571 y 1700 , este delito representó aproximadamente el $20 \%$ de los juzgados por la Inquisición y, dentro de esta categoría, las condenas a relajación en persona y en estatua fueron del 7 y el 20, 3\% respectivamente (Alberro, 1998: 207). Estos datos y el hecho de que las mujeres procesadas por la Inquisición en México no representaran más del $25 \%$, por tanto, evidencian que el caso central narrado en la novela no fue en absoluto común. No obstante, supuso un efectivo instrumento de captación de la atención del público lector, tanto por los elementos con los que pudieron identificarse como por la ficción que lo acompañó, dotándolo de un carácter aún más extraordinario.

\section{3. "El vulgo no es más que el vulgo"}

Los esfuerzos por crear una ciudadanía que dejase atrás las distinciones étnicas y culturales y fuese capaz de identificarse con un modelo de civilización nacional mexicana formaron parte de una tendencia intelectual que se venía sucediendo en el plano literario, desde la guerra de independencia (Illades, 2003: 11-19). A pesar de

${ }^{5}$ Ley 35, Tít. 1, libro VI, tít. I, ley 35 de la Recopilación (1681).

${ }^{6}$ La relajación al brazo secular en persona consistía en la entrega de los condenados por la Inquisición a las autoridades virreinales para que éstas pronunciaran y ejecutaran la sentencia a muerte.

${ }^{7}$ Ante la ausencia del reo, se quemaba una estatua para simbolizar la ejecución de la sentencia. 
estos esfuerzos, aun en la segunda mitad de la centuria, las elites intelectuales defensoras del gobierno juarista siguieron constatando la necesidad de llevar a cabo un esfuerzo pedagógico homogeneizador capaz de eliminar mediante su asimilación las identidades, adscripciones y modos de vida incompatibles con el orden socio-político que éstas defendían. En este contexto, Vicente Riva Palacio colaboró en el desarrollo de un proyecto cultural, liderado por Ignacio Ramírez e Ignacio Manuel Altamirano, que estuvo basado en la recuperación del concepto criollo de patria y en su reelaboración mediante la asociación con los principios liberales y republicanos.

La presencia a mediados de la centuria de importantes brechas entre el modelo de ciudadanía defendido desde las instancias liberales y el cuerpo social no respondió, exclusivamente, a cuestiones ligadas al mantenimiento de los privilegios eclesiásticos o corporativos sino que estuvo ligada también a la existencia de formas de vida y tradiciones interpretadas como muestras de un atraso civilizatorio por parte de esta elite política. Entre las múltiples divergencias que supusieron un rasgo definitorio de la otredad popular, las minorías ilustradas centraron su atención en las formas de apropiación y uso de los espacios. Ya desde las reformas iniciadas a finales del siglo XVIII fueron puestos de manifiesto dos modos opuestos de entender el uso de los espacios comunes. Junto con la interpretación ilustrada, basada en la regulación europea del uso y disfrute de las zonas públicas por parte del poder político, convivió otra forma popular de apropiación de estas áreas, entendidas como espacios cotidianos en donde lo público y lo privado confluían (Prieto, 2001: 9).

Estos comportamientos, discordes con los códigos de conducta pública avalados por las élites, crearon diversas muestras de rechazo por parte de las autoridades. La obra Enfermedades políticas que padece la capital de esta Nueva España, escrita en 1785 por el alcalde mayor del virreinato, Hipólito Villarroel, ejemplificaba lo afirmado, sosteniendo acerca de la ciudad de México:

es un bosque impenetrable, lleno de malezas y precipicios que se hace inhabitable a la gente culta; lleno de escondites y de agujeros donde se alberga la gente soez, a los que con más propiedad se les debe dar el nombre de zahúrdas que de casas de habitación de racionales, por contener cada una un enjambre de hombres y mujeres sucios y asquerosos que son la abominación de los demás por sus estregadas vidas y sus costumbres, perfectos lupanares de infamias. (Villarroel, 1994: 187)

Esta actitud despreciativa por parte de las elites intelectuales con respecto a ciertos modos de vida y uso de los espacios comunes por parte de la otredad popular se mantuvo en las décadas siguientes a la independencia política del país. La recreación de la sociedad novohispana de la época, elaborada casi cien años después por el historiador Manuel Rivera Cambas, ofrece un interesante ejemplo al respecto. Al referirse a los beneficiosos resultados que tuvieron para la ciudad las reformas ilustradas promovidas por el virrey Revillagigedo, este autor afirmaba: "Hasta 1789, cada individuo del pueblo de México se consideraba con derecho incuestionable 
para disponer de las calles como de cosa propia; donde había un derrame de agua menos sucia allí se formaba un lavadero y se ponía una cuerda para secar la ropa" (Rivera, 1882: 30).

A lo largo del siglo XIX, por tanto, los sectores populares, cuyas costumbres, tradiciones y modos de vida no se adecuaban al estereotipo de hombre civilizado ${ }^{8}$, fueron situados en una categoría inferior por parte de la elite intelectual. La formulación de la sociedad civil, en términos liberales, basada en un paulatino reconocimiento de la igualdad jurídica entre los varones mayores de edad, convivió, así, con una amplia diversidad cultural y una profunda inequidad social. Las distinciones entre el pueblo, conceptualizado por los liberales como la base de la nación, y el "vulgo"" o el "populacho", caracterizado por el atraso, el fanatismo religioso, la violencia y la ignorancia, reflejaron esta situación y fueron comunes en los discursos y obras de los intelectuales de la época. "El vulgo no es el pueblo: el vulgo no es más que el vulgo", ponía Riva Palacio en boca de uno de los protagonistas de Monja y casada (1868: 316). En la novela, el autor describió a este sector poblacional despreciable como un conjunto social conflictivo, ligado al crimen, al desorden, a la vileza, a las pasiones descontroladas y, en general, a valores irreconciliables con el orden social defendido.

La relación del escritor con estos sectores socioeconómicos urbanos subalternos estuvo atravesada por su rechazo ante aquellas creencias, organizaciones y modos de vida que parecían incompatibles con el orden defendido. El deseo de educar a las masas para estimular su adscripción a una identidad nacional acorde con los valores cívicos, debía enfrentarse a una heterogeneidad étnica, al carácter indomable e independiente del "vulgo" y a la fuerte influencia que, se consideraba, seguía ejerciendo el poder eclesiástico sobre gran parte de la población capitalina.

\section{Homogenización étnica y nación}

El cese de la jurisdicción inquisitorial sobre la población indígena en 1571 supuso que el control de las posibles herejías y la moralidad del $80 \%$ de la población novohispana quedase en manos de los tribunales civiles y eclesiásticos. A inicios del siglo XVII, las áreas centrales de la ciudad de México, albergaban a la mayor

${ }^{8}$ La constitución de 1857 excluía de los derechos de ciudadanía a aquellas personas que no tuvieran "un modo honesto de vivir". Esta noción hacía referencia a un criterio económico al valorar el nivel de vida del individuo dentro del Estado (Ortiz, 2007: 324).

${ }^{9} \mathrm{El}$ empleo de este término como forma despectiva de referirse al "pueblo", resaltando su carácter ignorante e influenciable, fue habitual por parte de los centros de difusión de los discursos liberales y puso en evidencia la distancia existente entre la elite político-intelectual dirigente y el resto de la población a mediados del siglo XIX. 
parte de los españoles y criollos de la capital. En este marco espacial, en el que se emplazó la narración de Monja y Casada, la población negra y mulata fue notoriamente mayoritaria con respecto a la indígena (Mejía, 2004: 17). Esta situación, sin embargo, no explica la omisión que el autor hizo sobre la exención jurídica aludida con respecto a la Inquisición, algo que parece responder más al interés en suscitar la mayor animadversión posible de los lectores frente a la corporación inquisitorial.

Como resultado de estos objetivos, el autor contribuyó a la creación de una imagen magnificada de la presencia que el Tribunal de la Fe tuvo entre la población del Virreinato y relegó a un plano secundario a la población indígena en la formación histórica de la nación mexicana. La otredad indígena, de hecho, aparece en la obra relegada a una condición popular e ignorante, fuertemente influenciable por la demagogia eclesiástica, dependiente de las dádivas ofrecidas por las élites e interesada en su propio beneficio y no ya en el bienestar general de la nación ${ }^{10}$.

La narración del famoso tumulto de 1624 así lo demuestra, al adscribirse a los posicionamientos de las crónicas partidarias del Marqués de Gelves en las que los grupos indígenas aparecían caracterizados como seres pasivos, sometidos al influjo arzobispal y sin capacidad propia de acción. De esta manera, Riva Palacio ponía en boca del oidor Don Pedro de Vergara y Gaviria el reconocimiento de que a pesar de que los "indios naturales del país" seguían pagando el excesivo donativo exigido por el virrey, si el Arzobispo Don Juan Pérez de la Cerna "desaprobase todo lo practicado en una de sus pláticas u homilías, todos esos naturales" cambiarían automáticamente de bando (Riva, 1868: 307).

Esta imagen se vio complementada en la novela sólo con la figura del indio Ahuizote, un personaje vil que encarnaba la ausencia de valores cívicos y morales típica del vulgo y cuyos principales atributos eran el rencor contra los españoles y la ausencia de principios morales ante la satisfacción de sus propios intereses. Esta caracterización contrastaba con el carácter mestizo o español de los personajes centrales de la novela y aparecía asociada a una alteridad despreciable, además de subalterna, como muestra el siguiente pasaje: "en donde ahora existe el Paseo de la Alameda hubo en aquellos tiempos una especie de mercado miserable y solo frecuentado por los indios" (Riva, 1868: 51).

La sociedad colonial descrita aparecía constituida por múltiples grupos socioraciales caracterizados por su inmovilidad y condicionados por su genealogía. El autor denunciaba así las diversas fronteras étnicas: "en México estaban muy marcadas las razas. Españoles, indios, negros, mulatos: los hijos de español y negra, mulatos; los de español e india, mestizos; los de indio y negra, zambos; y luego una porción de subdivisiones, como pardos, coyotes, salta atrás" (Riva, 1868: 140). A

${ }^{10}$ La transmutación del tumulto de 1624 se centró en la manipulación que el poder eclesiástico ejerció sobre la ignorante y fanática población de la capital, obviando las tensiones entre la población indígena y las autoridades virreinales. 
pesar del rechazo manifestado ante esta desigualdad colonial, algo acorde con la desaparición de las barreras legales y la creación de la ciudadanía que se estaba viviendo en el país, la novela permite vislumbrar la vigencia, a mediados del siglo XIX, de una clasificación social con base en criterios raciales. En esta dirección y a modo de guiño hacia sus lectoras, Riva Palacio sostenía: "en nuestros tiempos y con las costumbres modernas, una mujer no se atrevería a encerrarse con un hombre, aunque éste fuera un negro, por temor a ese ¿qué dirán?”. El autor parece aquí convencido del común valor de la negritud como alteridad inferior entre su posible público. No obstante, a continuación, denuncia la cosificación de los esclavos afrodescendientes en el México del siglo XVII sosteniendo que: "entonces un negro, un esclavo no era un hombre y una dama no temía nunca por su reputación, aun cuando aquel negro pasase la noche en su mismo aposento; ;tanta era la distancia a que los colocaba el color, que ni la misma calumnia se atrevía a acercarlos!" (Riva, 1868: 43).

\section{Mujer y nación en el proyecto liberal}

Durante el siglo XIX, tanto conservadores como liberales coincidieron en el carácter masculino de la ciudadanía formal. El espacio destinado al ejercicio de la palabra y la acción en la potencialidad política fue un espacio vetado a las mujeres, consideradas seres complementarios y no sujetos activos.

En términos formales, la ciudadanía mexicana, en atención a la codificación constitucional llevada a cabo en el país entre 1824 y 1857, se definió como una cualidad perteneciente a las elites sociopolíticas del momento y, por tanto, como una característica exclusiva y excluyente de ciertos sectores poblacionales en función de su condición socio-económica, además de su edad, aunque no de su género ${ }^{11}$.

En la práctica, por tanto, la ausencia de reconocimiento de la ciudadanía femenina respondió a una interpretación concreta de la normativa formal ligada a la aceptación implícita por parte de las elites políticas de la relegación de las mujeres al ámbito doméstico. Esta escisión estuvo auspiciada por la reproducción que tanto conservadores como liberales llevaron a cabo de dos modelos de género opuestos: uno masculino, caracterizado por la razón, la firmeza y el intelecto para gobernar y otro femenino basado en la otredad, la sensibilidad y la intuición. Como ha afirmado Jaime Eduardo Ortiz, "la identificación de lo masculino con el orden civil y de lo femenino con el orden natural, hacía de lo femenino un principio de orden espiritual independiente del principio jurídico que daba origen al Estado" (Ortiz, 2007: 324). Esta identificación de lo masculino con lo público, llevaba implícita la asociación de lo femenino con la otredad, es decir, con lo doméstico y lo privado, excluyendo a las mujeres de las cuestiones relacionadas con el poder político.

11 Afirmación sustentada en el análisis de la Constitución Federal de 1824, las Leyes Constitucionales de 1836, las Bases Orgánicas de 1843 y la Constitución de 1857. 
A pesar de los violentos enfrentamientos que tuvieron lugar en la segunda mitad del siglo XIX entre liberales y conservadores, ambos conjuntos ideológicos coincidieron en la defensa de la funcionalidad social femenina como complemento y apoyo masculino mediante el ejercicio de las funciones de madre educadora de futuros ciudadanos y esposa complaciente. La actuación legislativa de los gobiernos liberales, con la vigencia del Decreto de gobierno del 30 de enero de 1854 sobre extranjería y nacionalidad ${ }^{12}$ o la aprobación de medidas como la Ley del 10 de agosto de $1857^{13}$ o la Ley de Matrimonio Civil de $1859^{14}$, regularon la posición femenina dentro del núcleo familiar, consolidando el matrimonio como la base institucional del orden social e instrumento definitorio de la nación institucionalizando la subordinación de las mujeres a la voluntad marital y masculina en general.

El desarrollo de medidas normativas de carácter formal tendentes a la limitación del papel femenino en la construcción nacional al ámbito doméstico no fue el único medio para regular los comportamientos de esta heterogénea mitad de la población. Además de la producción jurídica, la reproducción discursiva de estereotipos basados en una percepción de las mujeres como seres sexuales, objetos de deseo que, al mismo tiempo y de forma paradójica, debían garantizar el honor de sus familias a través de su castidad y la circunscripción de su conducta sexual a la esfera matrimonial, coadyuvó a la promoción efectiva del orden social deseado.

Si bien es cierto que esta feminidad prescriptiva apenas sufrió variaciones conceptuales que afectasen a su deber ser sexual desde las postrimerías coloniales, la ausencia de una implementación efectiva entre la población capitalina de esta normativa provocó una producción incesante de escritos defensores de una moralidad de indiscutible raíz cristiana ${ }^{15}$. El correcto funcionamiento del orden social, dentro del modelo liberal de ciudadanía, exigía reubicar las actitudes y los comportamientos femeninos disconformes con la normativa imperante, así como difundir un nacionalismo que crease sólidas lealtades hacia el nuevo estado. Para la realización de estos propósitos, la literatura y, en especial, la novela histórica de folletín, fungieron como eficientes instrumentos pedagógicos y disuasorios.

\section{El ideal femenino en la novela}

${ }^{12}$ Este decreto declaró la pérdida de la nacionalidad de las mexicanas que contrajesen matrimonio con un extranjero.

${ }^{13}$ Esta ley, llamada Ley de sucesiones por testamentaría y abintestato, prohibió, salvo escasas excepciones, la averiguación judicial de la paternidad.

${ }^{14}$ La Ley de 1859 dificultó el acceso al divorcio no vincular de aquellas mujeres víctimas de maltrato, además de reconocer explícitamente la obligación de las esposas de obedecer, agradar, asistir, consolar, aconsejar y venerar a sus respectivos maridos.

${ }^{15}$ La secularización de la sexualidad en el México Independiente no supuso la revocación del orden de valores asociado a los pecados de lujuria recogidos en la teología moral de Santo Tomás de Aquino. 
Pese a ser una novela dirigida a un público femenino (Riva, 1868: 130), la aparición de Monja y Casada en una publicación periódica como La Orquesta, respondió a la voluntad de extender también a la mentalidad masculina la reformulación liberal del modelo de feminidad. Al tratarse de una novela destinada a mujeres, sin embargo, la obra contuvo una importante carga melodramática, fruto de la aceptación y reproducción del arquetipo de feminidad basado en la sensibilidad y la emoción, muy presente en el movimiento romántico. La sencillez del lenguaje y estilo empleados en la obra perseguía el objetivo de llegar al mayor público posible, algo que Monja y casada logró, convirtiéndose en el libro más difundido de su autor. Pese a ello, la pertenencia de sus protagonistas a los sectores más acomodados de la sociedad colonial, así como las referencias al pueblo como parte de una otredad, en ocasiones despreciable, mostraron la complicidad del autor con las elites socioeconómicas del siglo XIX y sus modos de vida.

El éxito de la obra se manifestó, principalmente, entre las mujeres que compartían el hábito cultural de dedicar tiempo a la lectura ociosa ${ }^{16}$ y un código de valores ligados al ideal de amor romántico. Sólo aquellas que hubiesen adquirido una sensibilidad acorde con estos cánones se podrían sentir embaucadas por la narrativa de la novela ya que a lo largo de ésta, el motor de los personajes femeninos no era otro que la satisfacción de sus pretensiones amorosas. El amor, junto con la patria, aparecían en Monja y casada como conceptos abstractos, ahistóricos, universales y virtuosos. Al respecto, sostenía el narrador: "cualquier pasión grande que domine el corazón engrandece el alma, bien sea el sentimiento religioso, o el amor, o el patriotismo" (Riva, 1868: 35). Asimismo, advertía que "aunque se rían nuestras lectoras" los enamorados ya se buscaban los pies bajo la mesa en 1615 ya que "el amor es como los chinos, no varía de modas" (Riva, 1868: 130).

Se trataba, por otro lado, de un amor occidentalizado, un amor que había experimentado un proceso de "subjetivización, individuación y privatización"17, que luchaba contra la moralidad de la época, en este caso del siglo XVII mexicano, y que aparecía como el principal motor de vida de los protagonistas. "Entre amantes se arreglan en una hora cosas más difíciles y atrevidas, que en los congresos y en las asambleas en un año", bromeaba el autor, contraponiendo el universo del amor, femenino por excelencia, al de los asuntos políticos, del que las mujeres estaban excluidas.

Junto con la acción política, el trabajo aparecía como un concepto perteneciente al género masculino en la novela. Riva Palacio se adscribía así al ideal de domesti-

${ }^{16}$ No debían de estar forzadamente alfabetizadas ya que la lectura de la prensa en grupo, tanto en los espacios públicos como en los privados, era una práctica muy extendida en la época.

${ }^{17}$ Coincide con el concepto de amor observado por Fridhelm Schmidt en las obras de Ignacio Manuel Altamirano (Schmidt, 1999:100). 
cidad, según el cual las mujeres debían tener un espacio de actuación limitado al desempeño de las labores domésticas centradas en el cuidado de hijos y maridos. Lo afirmado se sustenta en el hecho de las únicas personajes que jugaron un papel activo en la esfera pública, tanto política como laboral, fueron mujeres condenables desde el punto de vista ético del autor.

Las características de Luisa, una de las principales antagonistas de la novela, ejemplifican esta estrategia disuasoria. Esclava de extraordinaria belleza, mulata y malvada, tras engañar y abusar de la bondad de su amo, el español Don José de Abalabide, acusándolo de hereje falsamente ante la Inquisición, transcurre sus días volcada en el placer personal, material y carnal. Su participación en los tumultos políticos novelados es activa y constante, al igual, que su sexualidad pecaminosa. A través de diversos ardides, que incluyen la seducción de hombres pudientes, logra satisfacer sus aspiraciones hasta que un cambio providencial de su suerte la hace caer en múltiples desgracias.

Al igual que Luisa, otras mujeres que lograron con sus actividades no depender de un sustento marital, fueron presentadas en la novela como seres egoístas, movidos por intereses personales y alejados del tan ensalzado ideal de amor romántico. La perversa bruja Sarmiento, mujer de aspecto horrible que es capaz de entregar a su propia hija a cambio de dinero, o la traidora curandera Bárbara, que con el mismo fin favorece el rapto de la inocente Blanca de Mejía, protagonista de Monja y Casada, son muestra de ello. Ambas, al tener una edad avanzada y no poder seducir a hombres para servirse de sus favores, alcanzaron su autonomía económica mediante un uso pernicioso de conocimientos ancestrales para la realización de ungüentos y pócimas de efectividad variable.

La condena moral del comportamiento de estas mujeres y su contraposición a los de otras personajes ensalzadas en la obra por el autor, como la casta y sumisa Blanca de Mejía, protagonista de la obra, o Servia, esclava tímida y servicial, muestran el desarrollo de una estrategia persuasiva y orientada a la defensa de un modelo de feminidad centrado en el amor romántico como principal objetivo vital y en el desempeño de labores domésticas como única actividad no reprobable.

Otro de los objetivos de la estrategia pedagógica orientada a la regulación de los comportamientos femeninos fue el fomento de una animadversión entre las lectoras frente a las instancias políticas conservadoras y defensoras de los privilegios eclesiásticos. Para ello, el autor centró su crítica en el fanatismo religioso de personajes como Felisa y Beatriz. Felisa era una criada que servía en el convento donde Blanca de Mejía había sido enclaustrada a través de engaños. Tras ayudar a Blanca a escapar del convento y decidir huir con ella, logró esquivar a los familiares de la Inquisición pero el peligro sobrevenido fue interpretado por esta mujer, "con toda resolución de las pasiones fanáticas" (Riva, 1868: 35), como una señal divina de que debían permanecer de por vida en el convento donde servían. Beatriz, madrina de la protagónica Blanca de Mejía, por su parte, es descrita por Riva Palacio como una "azucena que se marchitaba con el fuego del fanatismo", por preferir el convento a 
un posible matrimonio futuro. Tanto Felisa como Beatriz, fueron representadas como mujeres que sacrificaron sus vidas personales y amorosas a causa de la superstición o excesiva creencia religiosa. De esta manera, Riva Palacio desarrolló de forma crítica la imagen de mujeres sumidas en absurdas creencias a causa de su condición de seres débiles e ignorantes, potencialmente vulnerables ante la manipulación eclesiástica, lo que concordaba con el discurso liberal imperante en la época.

\section{Conclusiones}

El rechazo ante la desigualdad racial y su contraposición a una supuesta igualdad de la sociedad estuvo acompañado en Monja y casada por la identificación homogenizada del elemento indígena ${ }^{18} \mathrm{y}$ el desarrollo de acciones tendentes a su asimilación. Tanto el "indio" como la "mujer" representaron una amenaza para la consolidación del proyecto liberal de estado nación al aparecer representados en los discursos de la época como seres débiles, sumidos en la ignorancia y, por consecuencia, en la tutela eclesiástica.

Los mecanismos de incorporación a la ciudadanía de ambos sujetos - mujeres y minorías socio-étnicas- partieron, por tanto, de la aceptación de una posición subordinada en el enjambre estatal aunque teorizada de distinta manera. Las mujeres debían ocupar los roles de esposas y madres de futuros ciudadanos, obedeciendo la autoridad patriarcal dentro y fuera del núcleo doméstico. Los indígenas, por su parte, podían abandonar su condición étnica y convertirse en ciudadanos mexicanos de pleno derecho, dejando atrás su cultura y modo de vida y abrazando el individualismo liberal. Como indios, sin embargo, ocuparían una posición secundaria dentro de la nueva República, cuyos mecanismos tratarían, por todos los medios, de integrarlos mediante su eliminación.

Llevar a cabo una investigación histórica acerca del origen y el desarrollo de identidades asociadas a la construcción del Estado nacional es una compleja tarea que implica adentrarse en un heterogéneo universo simbólico de producción y asimilación, en el que las múltiples percepciones sobre el "otro" y, por supuesto, la conciencia de uno mismo, no siempre dejan una huella rastreable. Pese a ello, los múltiples esfuerzos realizados desde las élites liberales por implementar determinadas formas de vida acordes con un proyecto de ciudadanía nacional parecen indicar que la batalla contra la diversidad poblacional preexistente no fue sencilla. Más allá de sus logros o fracasos, este trabajo ha querido resaltar cómo la novela Monja y casada, virgen y mártir formó parte del proceso de reconstrucción del pasado histó-

${ }^{18}$ En la novela el concepto colonial de "indio" sigue aplicándose como categoría reduccionista, en contraposición a la riqueza y diversidad cultural que caracterizaba a la población indígena. 
rico como estrategia para la creación de una conciencia nacional y la promoción entre hombres y mujeres de un orden étnico y de género específico.

El desarrollo de una temporalidad lineal evolutiva en la novela operó en defensa del programa reformista liberal. De esta manera, la descripción de un pasado colonial eclipsado por el omnipresente poder inquisitorial permitió la identificación de diversas otredades a través de las cuales se erigió el modelo nacional mexicano: el poder eclesiástico, el gobierno español y el elemento indígena, fruto este último de la férrea división socio-racial auspiciada en la colonia. Como se ha ejemplificado en este trabajo, la presencia de saltos narrativos entre el pasado colonial del siglo XVII y el presente republicano, frecuentes en la novela, persiguió un doble objetivo: la creación en el imaginario colectivo de los lectores de un pasado común capaz de sentar las bases de la identidad nacional mexicana y el derrocamiento del yugo opresor simbolizado por la Iglesia y el poder conservador heredero de la colonia.

La voluntad de alejar a la Iglesia de los asuntos de Estado y reducir la influencia política que esta institución podía tener sobre la población mexicana estuvo acompañada del interés por regular la conducta sexual femenina con base a un código de valores acorde con la moral cristiana. La normativa formal amparada en el funcionamiento del estado como aparato coercitivo no fue el único ni el más efectivo instrumento para llevar a cabo este objetivo y también aquí la novela se erigió como un interesante medio de difusión de los modelos comportamentales. En este marco, el extraordinario éxito logrado por la obra literaria de Vicente Riva Palacio y, en especial, el obtenido por Monja y Casada ${ }^{19}$ supuso un fuerte impulso dentro de este proyecto y consolidó la imagen del autor como uno de los principales promotores del ideal de patria mexicana, de la identidad del mexicano mestizo y del modelo político liberal.

La búsqueda de una cohesión poblacional articulada en torno a una supuesta identidad nacional compartida y en contraposición a un enemigo externo común fue un aspecto constante en la construcción de múltiples estados-nación a lo largo del siglo XIX. Pese a no ser algo específico de la formación nacional mexicana, tratar de localizar los procesos y canales a través de los cuales esta construcción fue promovida sigue siendo pertinente para visualizar y comprender los instrumentos con los que, tanto ahora como en el pasado, el orden político busca legitimarse.

${ }^{19}$ La adaptación de la novela al cine en 1935 y la popular versión de la misma en la telenovela producida por Televisa en 1986 fueron consecuencias del suceso indicado. 


\section{BIBLIOGRAFÍA}

AlBERRO, Solange.

1998 Inquisición y Sociedad en México. 1571-1700. México: Fondo de Cultura Económica.

ALTAMIRANO, Ignacio.

1949 La literatura nacional. Revistas, ensayos, biografías y prólogos. México: Ed. J. L. Martínez.

ANDERSON, Benedict.

1993 Comunidades Imaginadas. Reflexiones sobre el origen y la difusión del nacionalismo. México: Fondo de Cultura Económica.

FEHER, Eduardo Luis.

2010 "Hidalgo. Inquisición e independencia en la sociedad novohispana", en Comisión Organizadora de los Festejos del Bicentenario y Centenario de la Revolución Mexicana (ed.), La independencia de México. A 200 años de su inicio pensamiento social y jurídico. México: UNAM, 2010, pp. 99-135.

GARCÍA-Molina RiMElQUe, Antonio M.

1999 El régimen de penas y penitencias en el Tribunal de la Inquisición de México. México: Instituto de Investigaciones Jurídicas, UNAM, 1999.

ILLADES AGUIAR, Carlos.

2003 "Lo nacional-popular en el romanticismo mexicano", en Casa del Tiempo, vol. V, núm. 58, 2003, pp. 11-19.

MEJÍA, Edgar.

2004 "La ciudad amenazada: rebeliones de negros y fantasías criollas en una crónica de la ciudad de México del siglo XVII", en Colorado Review of Hispanic Studies, núm. 2, 2004, pp. 7-23.

ORTIZ LEROUX, Jaime Eduardo.

2007 "El sujeto de la ciudadanía en la constitución mexicana", en Revista del Posgrado en Derecho de la UNAM, núm. 5, 2007, pp. 319-334.

PRIETO HERnÁndEZ, Ana María.

2001 Acerca de la pendenciera e indisciplinada vida de los léperos capitalinos. México: Conacultla.

RIVA PALACIO, Vicente.

1861 "Anales de la Inquisición de México", en Monitor Republicano, 31 de mayo 1861.

RIVA PALACIO, Vicente.

1868 Monja y Casada, Virgen y Mártir. Historia de los tiempos de la Inquisición. México: Imprenta de la Constitución Social. 
RIVERA CAMBAS, Manuel.

1882 México pintoresco, artístico y monumental, México: Imprenta de la Reforma.

SCHMIDT, Fridhelm.

1999 "Amor y nación en las novelas de Ignacio Manuel Altamirano", en Literatura Mexicana, núm. 1.2, 1999, pp. 97-117.

SoOK KIM, Yun.

2007 "Desde la Historia -y en la historia- hasta la identidad política: estrategia narrativa del General Vicente Riva Palacio en Monja y casada y Martín Garatuza", en ConNotas.Revista de crítica y teoría literarias, vol. V, núm. 9, 2007, 53-68.

SUÁREZ, Escobar, Marcela.

1994 Sexualidad y norma sobre lo prohibido. La Ciudad de México y las postrimerías del virreinato. México: Fac. Filosofía y Letras, UNAM.

VILLARROEL, Hipólito.

1994 Enfermedades políticas que padece la capital de esta Nueva España. México: Consejo Nacional para la Cultura y las Artes. 